\title{
Acute Renal Failure in Hospitals in Togo: Comparative Analysis of HIV Positive Patients and HIV Negative Patients
}

\author{
Yawovi Mawufemo Tsevi ${ }^{*}$, Lidaw Deassoua Bawe², Komi Dzidzonu Nemi³ ${ }^{3}$ Akouda Patassi², \\ Ihou Majesté Wateba²
}

${ }^{1}$ Department of Nephrology and Hemodialysis, University Hospital Sylvanus Olympio of Lomé, University of Lome, Lome, Togo ${ }^{2}$ Departement of Infectious and Tropical Diseases, University Hospital Sylvanus Olympio of Lomé, University of Lome, Lome, Togo ${ }^{3}$ Department of Internal Medicine, University Hospital Sylvanus Olympio Lomé, University of Lome, Lome, Togo

Email: ^tseviclaude@gmail.com

How to cite this paper: Tsevi, Y.M., Bawe, L.D., Nemi, K.D., Patassi, A. and Wateba, I.M. (2019) Acute Renal Failure in Hospitals in Togo: Comparative Analysis of HIV Positive Patients and HIV Negative Patients. Open Journal of Nephrology, 9, 77-86. https://doi.org/10.4236/ojneph.2019.93009

Received: August 4, 2019

Accepted: September 3, 2019

Published: September 6, 2019

Copyright $\odot 2019$ by author(s) and Scientific Research Publishing Inc. This work is licensed under the Creative Commons Attribution International License (CC BY 4.0).

http://creativecommons.org/licenses/by/4.0/

\begin{abstract}
Introduction: Human Immunodeficiency (HIV) is a risk factor often associated with the occurrence of Acute Renal Failure (ARF). Objectives: To describe the profile of Acute Renal Failure (ARF) in HIV-infected patients and compare them to non-infected patients. Patients and Methods: It was a prospective study from January 2018 to February 2019 that took place in the nephrology, infectious diseases and internal medicine departments of the Sylvanus Olympio University Hospital Center in Lomé (Togo). Results: The prevalence of ARF in HIV-infected patients was 48.07\%. HIV-infected patients had an average age of $46.9 \pm 11.6$ years $(\mathrm{p}=0.36)$ compared to $44.0 \pm$ 20.4 years for non-HIV infected patients. Female sex was predominant in the HIV-infected population with a sex ratio H/F of $0.6(\mathrm{p}<0.0001)$ versus 2.9 for the non-infected. The reasons for admission were such as fever $(28 \%)$, digestive disorders (56\%) were more common in HIV-infected patients than non-infected patients $(11.1 \%, 37 \%)$. Infected patients had more diarrhea than non-infected patients $(24 \%$ versus $7.4 \%)$ with $\mathrm{p}=0.01$. They showed more signs of infections than uninfected patients ( $40 \%$ versus $18.5 \%$ ) with $\mathrm{P}=0.02$. HIV infection was known before admission in $96 \%$ of cases. Patients whose HIV was known before admission had hypertension (16.7\%), diabetes $(12.5 \%)$ and CD4 count $<200\left(/ \mathrm{mm}^{3}\right)$ in $50 \%$ of cases. HIV infected patients had more anemia $(52.0 \%$ versus $22.2 \%)$ with $\mathrm{p}=0.002$. Conclusion: No deaths were recorded in the HIV-infected group.
\end{abstract}

\section{Keywords}

ARF, HIV, Togo 


\section{Introduction}

Acute Renal Failure (ARF) is a generic term characterized by a sudden decrease in glomerular filtration rate resulting in the retention of nitrogenous waste [1]. In Africa, the causes of ARF are dominated by infections, toxic causes and gyneco-obstetrical causes [2]. Since the advent of HIV infection over the past two decades, several studies have described the incidence and causes of ARF in infected patients [2]. Indeed, before the introduction of HAART, opportunistic infections and deep immunosuppression were the most common conditions associated with episodes of acute renal failure (ARF) [3]. Currently, less than 10\% of ARFs are due to problems with nephrotoxicity of antiretrovirals [3].

In Togo, no studies on the prevalence of ARF in HIV-infected patients have yet been conducted. For us, it is therefore a question of looking for the particularities of ARF in HIV-infected patients and comparing them to non-infected patients.

\section{Materials and Methods}

\subsection{Case of Study}

Our study was carried out in the nephrology, internal medicine and infectious diseases departments of the Sylvanus Olympio University Hospital in Lomé. In addition to the care activities, these various services also carry out training and research activities.

\subsection{Type and Period of Study}

This was a prospective study from January 2018 to February 2019 that compared infected patients to HIV non-infected patients.

\subsection{Study Population}

It is based on an exhaustive sampling by reasoned choice of patients hospitalized in the Nephrology, Internal Medicine and Infectiology Department of the Sylvanus Olympio University Hospital of Lomé in Togo.

\subsection{Inclusion Criteria}

Included in our study were subjects of both sexes, all age included, and hospitalized for ARF. The HIV test was performed after informed consent of the patients. HAART was initiated after an initial biological checkup including (HIV typing, blood count-formula, CD4 count, serum creatinine, uremia, serum calcium and phosphoremia) and in agreement with the patient. Informed consent was obtained of all participants prior to data collection. The collection of information gathered as part of this study complied with the medical code of ethics.

\subsection{Criteria of Non-Inclusion}

Patients who were not hospitalized or who refused to participate in the study were not included. 


\subsection{Data Collection Technique}

The data were collected using a pre-established survey form with the following main variables: serum creatinine and plasma urea; demographic data (age, sex); comorbidities (diabetes mellitus, hypertension). Clinical data (reason for admission, blood pressure at admission, temperature, state of consciousness, state of hydration, diuresis and CDC classification of HIV infection), laboratory data (serum creatinine, plasma urea, calcium, phosphoremia, hemoglobin level, leukocyte count, platelets, cytobacterioligical urine exam, blood culture, HIV serology, CD4 cell count) and imaging data (renal echostructure) were also analyzed. A serum creatinine assay at D0, D3, D7 and at 3 months made it possible to evaluate the evolution of the ARF. This evolution was considered favorable if serum creatinine decreased by at least $50 \%$ compared to baseline creatinine. The causes of ARF such as sepsis, water loss, bleeding and administration of nephrotoxic drugs have been analyzed.

\subsection{Data Analysis Technique}

Data entry and statistical analysis were carried out using the EPI Info software version 2.4. A univariate analysis (5\% significance threshold) was performed using the chi2 test. The tables and figures were created using the EXCEL 2013 software.

\subsection{Parameters Definition}

- The ARF was defined according to K/DIGO recommendations [4], based on serum creatinine values determined in hospitalization. The ARF was also grouped into 3 stages according to K/DIGO recommendations [4].

- Oliguria is defined by diuresis of less than $500 \mathrm{ml} / 24$ hours.

- Anemia is defined for hemoglobin level below $12 \mathrm{~g} / \mathrm{dl}$ in women and $13 \mathrm{~g} / \mathrm{dl}$ in men. It has been described as severe for hemoglobin levels below $8 \mathrm{~g} / \mathrm{dl}$ in both sexes.

- Diabetes mellitus and high blood pressure have been diagnosed according to the World Health Organization (WHO) criteria.

- Sepsis was diagnosed in accordance with the consensus of the American College of Chest Physicians and the Society of Critical Care Medicine consensus.

- HIV infection has been classified according to the Center for Disease Control and Prevention (CDC) classification.

Data on the viral load of infected patients have not been analyzed. Indeed the viral load is not made at the beginning of antiretroviral treatment in our context in Togo; it is done after 6 months of well conducted treatment.

\section{Results}

A total of 104 patients were enrolled in this study, 50 of whom were HIV-infected, representing a prevalence of $48.07 \%$ of patients. HIV-infected patients had an average age of $46.9 \pm 11.6$ years with OR of 0.9 [IC $=0.9-1$ ] and $p=0.36$ versus $44.0 \pm 20.4$ years for non-HIV-infected patients (Table 1 ). The female sex was 
predominant in the HIV-infected population with an M/F sex ratio of 0.6 ( $\mathrm{p}<$ 0.0001 ) versus 2.9 for the uninfected (Table 1). The reasons for admission were such that fever (28\%), digestive disorders $(56 \%)$ were more common in HIVinfected patients than non-infected patients (11.1\%, 37\%). Clinically, HIV-infected patients had more infectious stigmas than non-infected patients during ARF with $\mathrm{p}=0.02$ (Table 1 and Table 2). Among the etiologies found, the presence of infection was associated with the occurrence of ARF ( $p=0.02)$ (Table 2). The presence of infectious diarrhea in HIV-infected patients was statistically related to the occurrence of ARF ( $p=0.01$ ) (Table 3). HIV infection was known before admission in $96 \%$ of cases. Patients whose HIV was known before admission had hypertension (16.7\%), diabetes (12.5\%) and CD4 count $<200\left(/ \mathrm{mm}^{3}\right)$ in $50 \%$ of cases as shown in Table 4. The general and clinical characteristic remains are grouped in Table 1, Table 4 and Table 5. HIV-infected patients had more anemia (52.0\% versus $22.2 \%$ ) with $\mathrm{p}=0.002$ (Table 6 ). This anemia was more severe in infected patients whose serological status was not known before admission $\mathrm{p}=0.02$ (Table 4). Regarding the staging of the ARF, no differences were found in the two groups (Table 6).

Table 1. General characteristics of patients with acute renal failure.

\begin{tabular}{|c|c|c|c|c|}
\hline Characteristics & HIV Positive & Non-Positive HIV & Value $\mathrm{p}$ & OR (IC 95\%) \\
\hline & $(n=50)$ & $(n=54)$ & & \\
\hline Average Age & $46.9 \pm 11.6$ & $44.0 \pm 20.4$ & 0.36 & $0.9(0.9-1.0)$ \\
\hline Sex-Ratio (M/F) & $0.6(18 / 32)$ & $2.9(40 / 14)$ & 0.0001 & - \\
\hline \multicolumn{5}{|l|}{ MR Risk Factors } \\
\hline High Blood Pressure & $16.0 \%(8 / 50)$ & $14.8 \%(8 / 54)$ & 0.86 & $1.1(0.3-3.2)$ \\
\hline Diabetes & $12.0 \%(6 / 50)$ & $7.4 \%(4 / 54)$ & 0.42 & $1.7(0.5-6.4)$ \\
\hline \multicolumn{5}{|l|}{ Reason for admission } \\
\hline Fever & $28.0 \%(14 / 50)$ & $11.1 \%(6 / 54)$ & 0.02 & $3.1(1.1-8.9)$ \\
\hline Loss of Consciousness & - & $7.4 \%(4 / 54)$ & 0.05 & $2.0(1.6-2.4)$ \\
\hline Dyspnea & $24.0 \%(12 / 50)$ & - & 0.0001 & $2.4(1.9-3.1)$ \\
\hline Digestive disorders & $56.0 \%(28 / 50)$ & $37.0 \%(20 / 54)$ & 0.05 & $2.0(1.6-2.4)$ \\
\hline Convulsion & - & $7.4 \%(4 / 54)$ & 0.05 & $2.0(1.6-2.4)$ \\
\hline Dysuria & $8.0 \%(4 / 50)$ & $14.8 \%(8 / 54)$ & 0.27 & $0.5(0.01-1.7)$ \\
\hline Oedema & $8.0 \%(4 / 50)$ & $7.4 \%(4 / 54)$ & 0.91 & $1.1(0.3-4.6)$ \\
\hline Renal failure & $56.0 \%(28 / 50)$ & $48.1 \%(26 / 54)$ & 0.42 & $2.0(1.6-2.4)$ \\
\hline Coma & - & $3.7 \%(2 / 54)$ & 0.17 & $1.9(1.6-2.4)$ \\
\hline Other Reasons & $12.0 \%(6 / 50)$ & $11.1 \%(6 / 54)$ & 0.89 & $1.1(0.3-3.7)$ \\
\hline \multicolumn{5}{|l|}{ Clinical Signs } \\
\hline Non Feverish Icterus & $5.0 \%(2 / 50)$ & $8.3 \%(4 / 54)$ & 0.53 & $1.8(1.5-2.3)$ \\
\hline Feverish Icterus & - & $8.3 \%(4 / 54)$ & 0.06 & $1.9(1.6-2.3)$ \\
\hline Non Febrile Coma & - & $100 \%(2 / 54)$ & 0.17 & $0.5(0.4-0.6)$ \\
\hline Gastroenteritis & $20.0 \%(8 / 50)$ & $20.8 \%(10 / 54)$ & 0.92 & $0.9(0.3-2.6)$ \\
\hline Pyelonephritis & $15.0 \%(6 / 50)$ & $8.3 \%(4 / 54)$ & 0.32 & $1.9(0.5-7.4)$ \\
\hline
\end{tabular}


Table 2. Comparison of Patients by ARF etiologies.

\begin{tabular}{ccccc}
\hline Etiologies & HIV Positive & Non Positive HIV & Value $\mathrm{p}$ & OR (IC 95\%) \\
\hline & $(\mathrm{n}=\mathbf{5 0})$ & $(\mathrm{n}=54)$ & & \\
\hline Water Loss & $28.0 \%(14 / 50)$ & $40.7 \%(22 / 54)$ & 0.17 & $0.06(0.2-1.3)$ \\
Haemorrhage & - & $3.7 \%(2 / 54)$ & 0.17 & $1.9(1.6-2.4)$ \\
Nephrotoxic drugs & $40.0 \%(20 / 50)$ & $25.9 \%(14 / 54)$ & 0.12 & $1.9(0.8-4.3)$ \\
Benign Tumor VU & - & - & - & - \\
Cancer & $8.0 \%(4 / 50)$ & $3.7 \%(2 / 54)$ & 0.34 & $2.6(0.4-12.9)$ \\
Infections & $\mathbf{4 0 . 0 \% ( 2 0 / 5 0 )}$ & $\mathbf{1 8 . 5 \% ( 1 0 / 5 4 )}$ & 0.02 & $2.9(1.2-7.1)$ \\
Other & $8.0 \%(4 / 50)$ & $3.7 \%(2 / 54)$ & 0.34 & $2.3(0.4-12.9)$ \\
\hline
\end{tabular}

UT: Urinary Tract.

Table 3. Distribution of patients by types of infection.

\begin{tabular}{ccccc}
\hline Types of Infections & HIV Positive & Non Positive HIV & Value $\mathrm{p}$ & OR (IC 95\%) \\
\hline & $(\mathrm{n}=\mathbf{2 0})$ & $(\mathrm{n}=10)$ & & \\
\hline Acute Pyelonephritis & $8.0 \%(4 / 50)$ & $3.7 \%(2 / 54)$ & 0.34 & $2.3(0.4-12.9)$ \\
Infectious Diarrhea & $\mathbf{2 4 . 0 \% ( 1 2 / 5 0 )}$ & $\mathbf{7 . 4 \% ( 4 / 5 4 )}$ & $\mathbf{0 . 0 1}$ & $\mathbf{3 . 9}(1.2-13.2)$ \\
Pleuro-Pneumopathy & $4.0 \%(2 / 50)$ & $3.7 \%(2 / 54)$ & 0.9 & $1.1(0.1-7.9)$ \\
Malaria & $4.0 \%(2 / 50)$ & $3.7 \%(2 / 54)$ & 0.9 & $1.1(0.1-7.9)$ \\
\hline
\end{tabular}

Table 4. Characteristics of HIV positive patients known or unknown before admission.

\begin{tabular}{|c|c|c|c|c|}
\hline \multirow[t]{2}{*}{ Parameters } & \multicolumn{2}{|c|}{ HIV Known before Admission } & \multirow[b]{2}{*}{ Value $p$} & \multirow[b]{2}{*}{ OR (IC 95\%) } \\
\hline & Yes $(n=48)$ & No $(n=2)$ & & \\
\hline Male Sex & $37.5 \%(18 / 48)$ & - & 0.97 & $1.1(1.0-1.2)$ \\
\hline High Blood Pressure & $16.7 \%(5 / 48)$ & - & 0.52 & $1.1(0.9-1.1)$ \\
\hline Diabetes & $12.5 \%(6 / 48)$ & - & 0.59 & $1.0(0.9-1.1)$ \\
\hline Water Loss & $29.2 \%(14 / 48)$ & - & 0.36 & $1.1(0.9-1.1)$ \\
\hline Nephrotoxic Drugs & $41.7 \%(20 / 48)$ & - & 0.23 & $1.1(0.9-1.1)$ \\
\hline Infections & $37.5 \%(18 / 48)$ & $100 \%(2 / 2)$ & 0.07 & $0.9(0.8-1.0)$ \\
\hline CD4 Count < $200\left(/ \mathrm{mm}^{3}\right)$ & $50.0 \%(24 / 48)$ & $100 \%(2 / 2)$ & 0.16 & $0.9(0.8-1.0)$ \\
\hline Cancer & $8.3 \%(4 / 48)$ & - & 0.67 & $1.0(0.6-1.1)$ \\
\hline AIDS Stage & $45.8 \%(22 / 48)$ & - & 0.2 & $1.1(0.9-1.2)$ \\
\hline ARF Stage 3 & $58.3 \%(28 / 48)$ & $100 \%(2 / 2)$ & 0.23 & $0.9(0.8-1.0)$ \\
\hline Anemia & $54.2 \%(26 / 48)$ & - & 0.13 & $1.1(0.9-1.2)$ \\
\hline Severe Anemia & $25 \%(12 / 48)$ & $100 \%(2 / 2)$ & 0.02 & $0.8(0.7-1.1)$ \\
\hline Other & $8.3 \%(4 / 48)$ & - & 0.67 & $1.0(0.9-1.1)$ \\
\hline
\end{tabular}


Table 5. Characteristics of patients with or without ARV triple therapy at admission.

\begin{tabular}{ccccc}
\hline Parameters & $\begin{array}{c}\text { ARV Triple } \\
\text { Therapy }\end{array}$ & & Value p & OR (IC 95\%) \\
& Yes (n = 34) & No (n = 14) & & \\
\hline Male Sex & $29.4 \%(10 / 34)$ & $57.1 \%(8 / 14)$ & 0.07 & $0.3(0.9-1.1)$ \\
High Blood Pressure & $17.6 \%(6 / 34)$ & $14.3 \%(2 / 14)$ & 0.77 & $1.3(0.2-7.3)$ \\
Diabetes & $11.8 \%(4 / 34)$ & $14.3 \%(2 / 14)$ & 0.81 & $0.8(0.1-4.9)$ \\
AIDS Stage & $52.9 \%(18 / 34)$ & $28.6 \%(4 / 14)$ & 0.12 & $2.8(0.7-10.7)$ \\
ARF Stage 3 & $64.7 \%(22 / 34)$ & $42.9 \%(6 / 14)$ & 0.16 & $2.4(0.1-1.6)$ \\
Anemia & $58.8 \%(20 / 34)$ & $42.9 \%(6 / 14)$ & 0.31 & $1.9(0.5-6.7)$ \\
Severe Anemia & $29.4 \%(10 / 34)$ & $14.3 \%(2 / 14)$ & 0.27 & $2.5(0.5-13.3)$ \\
CD4 count < 200 $\left(/ \mathrm{mm}^{3}\right)$ & $58.8 \%(20 / 34)$ & $28.6 \%(4 / 14)$ & 0.05 & $3.6(0.9-13.7)$ \\
Water Loss & $35.3 \%(12 / 34)$ & $14.3 \%(2 / 14)$ & 0.14 & $3.3(0.6-17.1)$ \\
Infections & $41.2 \%(14 / 34)$ & $28.6 \%(4 / 14)$ & 0.41 & $1.7(0.5-6.7)$ \\
Cancer & $5.9 \%(2 / 34)$ & $14.3 \%(2 / 14)$ & 0.33 & $0.3(0.1-2.9)$ \\
Other & $11.8 \%(4 / 34)$ & - & 0.18 & $1.4(1.2-1.8)$ \\
\hline
\end{tabular}

Table 6. Distribution of patients according to biological signs.

\begin{tabular}{ccccc}
\hline Biologiques Signs & HIV Positive & Non Positive HIV Value $\mathrm{p}$ & OR (IC 95\%) \\
\hline & $(\mathrm{n}=\mathbf{4 8})$ & $(\mathrm{n}=\mathbf{5 4})$ & & \\
\hline ARF Stage & & & & \\
Stage 1 & $32.0 \%(16 / 50)$ & $33.3 \%(18 / 54)$ & 0.88 & $0.9(0.4-2.1)$ \\
Stage 2 & $8.0 \%(4 / 50)$ & $7.4 \%(4 / 54)$ & 0.91 & $1.1(0.3-4.6)$ \\
Stage 3 & $60.0 \%(30 / 50)$ & $59.3 \%(32 / 54)$ & 0.93 & $1.0(0.5-2.2)$ \\
Plasma Urea & & & & \\
$>30$ mmol/L & $20.0 \%(10 / 50)$ & $40.7 \%(22 / 54)$ & 0.02 & $0.4(0.2-09)$ \\
Anemia & $\mathbf{5 2 . 0 \% ( 2 6 / 5 0 )}$ & $\mathbf{2 2 . 2 \% ( 1 2 / 5 4 )}$ & $\mathbf{0 . 0 0 2}$ & $\mathbf{3 . 8}(1.6-\mathbf{8 . 8})$ \\
Severe Anemia & $28.0 \%(14 / 50)$ & $18.5 \%(10 / 54)$ & 0.25 & $1.7(0.7-4.3)$ \\
\hline
\end{tabular}

\section{Discussion}

To our knowledge, this is the very first study in Togo that compares the characteristics of ARF in HIV-infected patients with those that are not infected. HIV prevalence was $48.07 \%$ in the surveyed ARF population. This prevalence was higher than that observed by KH Yao et al. [5] in Ivory Coast on a population of 414 patients (35.20\%) and even higher than that found in the Vachiat et al. [6] series (14.8\%) in South Africa, on a total of patients. However, our prevalence was similar to that found by de Ahoui et al. [7] in Cotonou (44.19\%) in HIV-infected patients newly put on HAART. In the general population, HIV prevalence varies from country to country in sub-Saharan Africa [8]. This contrasting aspect of HIV prevalence in sub-Saharan African studies can be explained by the diverse 
and complex combination of socio-cultural, economic and health factors affecting the HIV epidemic in each region of black Africa [9]. It has been shown that each region of Africa has a particular geographic facies of HIV that can explain its prevalence [8]. On the other hand, the selection bias in relation to our study scope would certainly have resulted in an increase in HIV prevalence in our ARF population. Indeed, the highest prevalences were found in studies [7] whose scope included the infectious disease department compared to studies whose scope included only nephrology and/or internal medicine services [5] [6]. Nevertheless, HIV prevalence remains high in the population of sub-Saharan Africa and leads to significant morbidity including acute renal failure. In a New York study of hospitalized HIV-infected patients, the risk of ARF before HAART initiation was $4.62 \%$ and that after treatment was $2.82 \%$ [10].

The age of occurrence of ARF was similar in the 2 groups of our study. Several authors had reported that HIV-infected patients developed ARF at an early age compared to uninfected patients [6] [11] [12] [13]. For example, Wyatt et al. [10], Vichiat et al. [6], KH Yao et al. [5] all reported that HIV-infected patients were significantly younger than those who were not HIV-infected respectively (44.2 years versus 56.6 years; $\mathrm{P}<0.001$ ), (37.4 years versus 45.2 years; $\mathrm{p}<0.001$ ) and (42 years versus 51 years; $\mathrm{p}<0.0001$ ). The female predominance of HIVinfected patients in our work complies with WHO data showing that there is a feminization of the HIV epidemic, especially in sub-Saharan Africa where women represent $61 \%$ of all infected adults [14]. This feminization of HIV infection has been found in some studies [5]. This female vulnerability is not only related to the susceptibility of heterosexual transmission, but also to the difficult socioeconomic conditions women face [15]. This large proportion of female sex in our study may also be related to the female predominance in the population of people living with HIV in our country. It should be noted, however, that male predominance has been reported in some studies [6] [10] [16].

Clinically, HIV-infected patients frequently had infectious and related water loss signs during ARF [5] [17]. However, comorbidities such as hypertension and diabetes were more common in uninfected patients. Similar observations had been reported by K. H. Yao et al. [5] in Ivory Coast. Severe immunosuppression is one of the main factors in the occurrence of kidney failure in our developing countries [6] [10] [16] [17]. Franceschini et al. [17] had shown that, low TCD4 level, high viral replication and AIDS stage were the factors associated with increased incidence of acute renal failure during HIV. As a result, the occurrence of ARF is only the consequence of opportunistic infections occurring during the illness. In our study, fever was more present in infected patients $(28.0 \%)$ than in non-infected patients $(11.1 \%)$ with $\mathrm{p}=0.02$; digestive disorders (56.0\% versus $37.0 \%)$ and $\mathrm{p}=0.05$. It was the same for infections $(40.0 \%$ versus $18.5 \%) \mathrm{p}=0.02$ and infectious diarrhea $(24.0 \%$ versus $7.4 \%) \mathrm{p}=0.01$. It has been reported in several studies [18] [19] [20] that infectious causes were a major etiology of ARF occurrence in HIV-infected patients. Rao and Friedman [19] [20] observed that half of patients with ARF also had sepsis. Similarly, Franceschini et 
al. [17] showed that the ARF was associated with an infectious cause in $52 \%$ of cases. According to Prakash et al., the factors of hypo-infusion and renal ischemia factors are the main causes of ARF in India [21]. Infectious causes and water losses were also the main risk factors for the occurrence of ARF in HIV-infected patients in our Togo series.

Biologically, anemia was predominant in the HIV-infected population also joining the series of Yao et al. [5]. Indeed, anemia is common during HIV infection [22] [23]. It may be secondary to isolated mechanisms, but most often entangled combining a context: inflammatory, blood spoliation, deficiency and medullary insufficiency.

No deaths were recorded in the HIV-infected population in our series, while lethality was comparable in both groups according to Yao et al. [5]. This confirms literature data that HIV infection does not increase the mortality rate of ARF patients [5]. The death of patients would be related more to the severity of the conditions responsible for ARF [6] [17].

The mordibity of ARF in patients living with HIV could be reduced by making an early diagnosis of the infection, by introducing at the diagnosis of antiretroviral treatment and especially by taking care of all the factors favoring the occurrence of an ARF.

\section{Conclusion}

The HIV-IRA association is common in hospitals in Lomé. Infectious causes and digestive disorders are the most common risk factors found. Early and effective care would improve the prognosis of these patients.

\section{Conflicts of Interest}

The authors declare no conflicts of interest regarding the publication of this paper.

\section{References}

[1] Lameire, N., Van, B.W., Vanholder, R., et al. (2005) Acute Kidney Injury. The Lancet, 365, 417-430. https://doi.org/10.1016/S0140-6736(05)70238-5

[2] Kalim, S., et al. (2008) Acute Kidney Injury in HIV-Infected Patients. In: Seminars in Nephrology, WB Saunders, Philadelphia, 556-562. https://doi.org/10.1016/j.semnephrol.2008.08.008

[3] Franceschini, N., Napravnik, S., Finn, W.-F., Szczech, L.-A. and Eron, J.-J. (2006) Immunosuppression, Hepatitis $C$ Infection and Acute Renal Failure in HIV-Infected Patients. Journal of Acquired Immune Deficiency Syndromes, 42, 368-372. https://doi.org/10.1097/01.qai.0000220165.79736.d3

[4] Khwaja, A. (2012) Clinical Practice Guideline for Acute Kidney Injury. Nephron Clinical Practice, 120, c179-c84.

[5] Yao, K.H., Tanon, A.K., Lagou, A.D., et al. (2017) Etude comparative de l'insuffisance rénale aigue communautaire chez le sujet VIH positif et le sujet VIH négatif: Expérience d'un service de médecine interne à Abidjan (Côte d'Ivoire). Néphrologie et Thérapeutique, 13, 168-175. 
https://doi.org/10.1016/j.nephro.2016.10.003

[6] Vachiat, A.I., Musenge, E., Wadee, S. and Naicker, S. (2013) Renal Failure in HIVPositive Patients: A South African Experience. Clinical Kidney Journal, 6, 584-589. https://doi.org/10.1093/ckj/sft128

[7] Ahoui, S., Dovonou, C.A., Vigan, J., et al. (2016) Incidence et facteurs associes a l'insuffisance rénale aigue chez les personnes vivantes avec le virus d'immunodéficience acquise (PVVIH) traitées par le tenofovir au CHUD-B en 2015. Cahiers du CBRST, 9, $100-112$.

[8] Amat-Roze, J.-M. (2003) L'infection à vih/sida en afrique subsaharienne, propos géographiques. Hérodote, 111, 117-155. https://doi.org/10.3917/her.111.0117 https://www.cairn.info/revue-herodote-2003-4-page-117.htm

[9] Temah, C.T. (2009) Les déterminants de l'épidémie du vih/sida en afrique subsaharienne. Revue déconomie du développement, 17, 73-106.

https://doi.org/10.3917/edd.231.0073

https://www.cairn.info/revue-d-economie-du-developpement-2009-1-page-73.htm

[10] Wyatt, C.M., Arons, R.R., Klotman, P.E., et al. (2006) Acute Renal Failure in Hospitalized Patients with HIV: Risk Factors and Impact on Inhospital Mortality. AIDS, 20, 561-565. https://doi.org/10.1097/01.aids.0000210610.52836.07

[11] Islam, F.M., Wu, J., Jansson, J. and Wilson, D.P. (2012) Relative Risk of Renal Disease among People Living with HIV: A Systematic Review and Meta-Analysis. BMC Public Health, 12, 234. https://doi.org/10.1186/1471-2458-12-234

[12] Ibrahim, F., Naftalin, C., Cheserem, E., et al. (2010) Immunodeficiency and Renal Impairment Are Risk Factors for HIV-Associated Acute Renal Failure. AIDS, 24, 2239-2244. https://doi.org/10.1097/QAD.0b013e32833c85d6

[13] Lopes, J.A., Melo, M.J., Viegas, A., et al. (2011) Acute Kidney Injury in Hospitalized HIV-Infected Patients: A Cohort Analysis. Nephrology Dialysis Transplantation, 26, 3888-3894. https://doi.org/10.1093/ndt/gfr192

[14] UNAIDS (2007) The Joint United Nations Programme on HIV/AIDS. UNAIDS/WHO.

[15] Akinyi Magadi, M. (2011) Understanding the Gender Disparity in HIV Infection across Countries in Sub-Saharan Africa: Evidence from the Demographic and Health Surveys. Sociology of Health \& Illness, 33, 522-539. https://doi.org/10.1111/j.1467-9566.2010.01304.x

[16] Franceschini, N., Napravnik, S., Eron, J.J., et al. (2005) Incidence and Etiology of Acute Renal Failure among Ambulatory HIV-Infected Patients. Kidney International, 67, 1526-1531. https://doi.org/10.1111/j.1523-1755.2005.00232.x

[17] Fabian, J. and Naicker, S. (2009) HIV and Kidney Disease in Sub-Saharan Africa. Nature Reviews Nephrology, 5, 591-598. https://doi.org/10.1038/nrneph.2009.141

[18] Rao, T.K. (2001) Human Immunodeficiency Virus Infection and Renal Failure. Infectious Disease Clinics of North America, 15, 833-850. https://doi.org/10.1016/S0891-5520(05)70175-6

[19] Rao, T.K., Friedman, E.A. and Nicastri, A.D. (1987) The Types of Renal Disease in the Acquired Immunodeficiency Syndrome. The New England Journal of Medicine, 316, 1062-1068. https://doi.org/10.1056/NEJM198704233161705

[20] Rao, T.K. and Friedman, E.A. (1995) Outcome of Severe Acute Renal Failure in Patients with Acquired Immunodeficiency Syndrome. American Journal of Kidney Diseases, 25, 390-398. https://doi.org/10.1016/0272-6386(95)90099-3

[21] Prakash, J., Gupta, T., Prakash, S., Rathore, S.S. and Sunder, S. (2015) Acute Kidney Injury in Patients with Human Immunodeficiency Virus Infection. Indian Journal of Nephrology, 25, 86-90. https://doi.org/10.4103/0971-4065.138696 
[22] McClure, M., Singh, G.J., Rayment, M., Jones, R. and Levy, J.B. (2012) Clinical Outcomes of a Combined HIV and Renal Clinic. Clinical Kidney Journal, 5, 530-534. https://doi.org/10.1093/ckj/sfs141

[23] Hamzic-Mehmedbasic, A., Rebic, D., Balavac, M., Muslimovic, A. and Deemizic, J. (2015) Clinical Analysis of Etiology, Risk Factors and Outcome in Patients with Acute Kidney Injury. Materia Socio Medica, 27, 71-74.

https://doi.org/10.5455/msm.2015.27.71-74 